\title{
Comparison of the Diagnostic Accuracy of Monocyte Distribution Width and Procalcitonin in Sepsis Cases in the Emergency Department: A Prospective Cohort Study
}

\section{CHIH-HUANG LI}

Chang Gung Medical Foundation

Chen-June Seak

Chang Gung Medical Foundation

Chung-Hsien Chaou

Chang Gung Medical Foundation

Tse-Hsuan Su

Chang Gung Medical Foundation

\section{SHI-YING GAO}

Chang Gung Medical Foundation

Cheng-Yu Chien

Chang Gung Medical Foundation

CHIP-JIN NG ( $\nabla$ ngowl@ms3.hinet.net)

Chang Gung Medical Foundation https://orcid.org/0000-0003-0363-2938

Research article

Keywords: Monocyte, sepsis, biomarker, diagnosis, emergency department

Posted Date: April 20th, 2021

DOI: https://doi.org/10.21203/rs.3.rs-410760/v1

License: (c) (1) This work is licensed under a Creative Commons Attribution 4.0 International License. Read Full License

Version of Record: A version of this preprint was published at BMC Infectious Diseases on January 4th, 2022. See the published version at https://doi.org/10.1186/s12879-021-06999-4. 


\section{Abstract}

Background: Early diagnosis and treatment of patients with sepsis reduce mortality significantly. In terms of exploring new diagnostic tools of sepsis, monocyte distribution width (MDW), as part of the white blood cell (WBC) differential count, was first reported in 2017. MDW greater than 20 and abnormal WBC count together provided a satisfactory accuracy and was proposed as a novel diagnostic tool of sepsis. This study aimed to compare MDW and procalcitonin (PCT)'s diagnostic accuracy on sepsis in the emergency department.

Methods: This was a single-center prospective cohort study. Laboratory examinations including CBC/DC, MDW, PCT were obtained while arriving at the ED. We divided patients into non-infection, infection without sepsis, sepsis, and sepsis-3 groups. This study's primary outcome is the sensitivity and specificity of MDW, PCT, and MDW+WBC in differentiating septic and non-septic patients. The cutoff value for MDW was established to maximize sensitivity at an optimal level of specificity.

Results: From May 2019 to September 2020, 402 patients were enrolled for data analysis. Patient number in each group was: non-infection 64 (15.9\%), infection without sepsis $82(20.4 \%)$, sepsis $202(50.2 \%)$, sepsis-3 15 (7.6\%). The AUC of MDW, PCT, and MDW+WBC to predict sepsis was $0.753,0.704$, and 0.784 , respectively. ( $p<0.01)$ The sensitivity, specificity, PPV, and NPV of MDW using 20 as the cutoff in predicting sepsis were $86.4 \%, 54.2 \%, 76.4 \%$, and $70 \%$, compared to $32.9 \%, 88 \%, 82.5 \%$, and $43.4 \%$ using $0.5 \mathrm{ng} / \mathrm{mL}$ as the PCT cutoff value. On combing MDW and WBC count, the sensitivity and NPV further increased to $93.4 \%$ and $80.3 \%$, respectively. In terms of predicting sepsis-3, the AUC of MDW, PCT, and MDW+WBC was $0.72,0.73$, and 0.70 , respectively. MDW, using 20 as cutoff, exhibited sensitivity, specificity, PPV, and NPV of $90.6 \%, 37.1 \%, 18.7 \%$, and $96.1 \%$, respectively, compared to $49.1 \%, 78.6 \%$, $26.8 \%$, and $90.6 \%$ when $0.5 \mathrm{ng} / \mathrm{mL}$ PCT was used as cutoff.

Conclusions: In conclusion, MDW is a more sensitive biomarker than PCT in predicting sepsis/sepsis-3 in the ED. MDW $<20$ shows a higher NPV to exclude sepsis-3. Combining MDW and WBC count further improves the accuracy in predicting sepsis but not sepsis-3.

Trial registration: The study was approved by the Institution Review Board of Chang Gung Memorial Hospital, Taoyuan, Taiwan (No. 201900442B0) and registered to the ClinicalTrial.gov (NCT04322942).

\section{Background}

Sepsis is a life-threatening organ dysfunction caused by a dysregulated host response to infection.[1-3] The average mortality due to sepsis is about 30 to 40\%.[4, 5] Despite the new Sepsis-3 definition that focuses mainly on patients with the worst outcome, early recognition and diagnosis of sepsis had been an essential part of sepsis treatment. According to the surviving sepsis campaign, the early identification and management of sepsis remain unchanged.[6] 
There is a significant unmet clinical need for a test for the early detection of patients having or developing sepsis. Although the detection and treatment of sepsis are frequently delayed, more rapid administration of sepsis-specific treatments, particularly antibiotics, are associated with improved clinical outcomes, including significantly reduced mortality.[7-9] One of the common causes of sepsis misdiagnosis is the lack of its recognition and contributes to adverse consequences due to delays in definitive antimicrobial treatments.[10]

Emergency Departments (EDs) have initiated measures to detect sepsis as early as possible, but there still exists the need for a reliable biomarker of sepsis. Existing biomarkers of sepsis such as C-reactive protein (CRP), procalcitonin (PCT), and lactate tests are ordered only if the clinician has already observed a high index of clinical suspicion of sepsis. The average reported accuracy was about 60 to $80 \%$.[11-14] PCT is more useful in guiding antimicrobial therapy than in early sepsis screening.[15-17] Recently, the biomarkers presepsin, interleukin-6 (IL-6), and neutrophil/lymphocyte ratio (N/M ratio) have been investigated. Nonetheless, the performance and the clinical significance of these biomarkers were not better than those of PCT.[18-24] A biomarker with higher sensitivity and negative predictive value (NPV) is mandatory for either early initiation of therapy or early discharge of the patients.

Several studies have suggested that Cell Population Data (CPD) parameters may be potentially useful. [25-27] Neutrophils and monocytes are among the first line to respond to a pathogenic signal generated by the microorganisms. In response to the pathogen-associated molecular patterns, the patternrecognition receptors on the cell surface are activated and the shape or size of the cells change accordingly. Currently, monocyte distribution width (MDW) is a CE-marked parameter, which can be reported along with complete blood counts (CBCs) from patients presenting to the ED. Crouser et al. showed that MDW has acceptable sensitivity and specificity and is potentially clinically useful for the early detection of patients with or developing sepsis in the ED; its area under the receiver operating characteristic curve (AUC) was 0.76 . They also reported that the diagnostic accuracy further improved by combining MDW with white blood cell (WBC) count.[28, 29] MDW also out-performed the systemic inflammatory response syndrome (SIRS) criteria and the quick SOFA (qSOFA) score.[30] A recent study showed that the performance of MDW was comparable to that of PCT in the infection ward.[31] WBC and differential count are among the most common laboratory tests ordered in patients with suspected infection. It can become a standard tool for the early detection of sepsis in the ED, where most sepsis cases are initially encountered. Despite the results published on these parameters, the performance comparison between MDW and PCT in the emergency department still remains to be assessed.

This study's primary outcome was to assess the sensitivity and specificity of MDW in differentiating septic and non-septic patients. The cutoff value for MDW was established to maximize sensitivity at an optimal level of specificity. Septic patients were identified as those with values equal to or above the MDW threshold and non-septic patients were those with MDW values below the threshold. Then, the performance of MDW and MDW + WBC count was compared to that of PCT. The study results were presented according to the regulation of Standards for Reporting Diagnostic accuracy studies (STARD). 


\section{Methods}

\section{Study design and setting}

This was a single-center prospective cohort study. We enrolled patients from the emergency department of a 3,000-bed medical center from July to October 2019. The average ED visits were 15,000 patients per month. The study was approved by the Institution Review Board of Chang Gung Memorial Hospital (No. 201900442B0) and registered to the ClinicalTrial.gov (NCT04322942).

\section{Selection of Participants}

A research coordinator worked full-time in the ED to screen all non-trauma patients from 8:30 to 17:30 $\mathrm{h}$, Monday to Friday. The inclusion criteria were: 1 . Adult $\geq 20$ years of age, 2 . Subjects presenting to the ED with the chief complaints of either fever, altered mental status, hypotension, or dyspnea, and 3. CBC count with differential testing was ordered, at presentation, as part of their standard medical care. The exclusion criteria were: 1 . Subjects previously enrolled in this study (subjects could not be enrolled more than once in this study), 2. Referred patients who had received antibiotic treatment, 3. Pregnant women, 4. MDW result not reported due to inefficient monocyte count, and 5. Subjects not able to understand or sign informed consent.

\section{Interventions}

No intervention was given to the patients or the caregivers in this study. The decision of blood test, antibiotic treatment, and patient disposition was taken entirely by the physician based on clinical examination. The patients were not enrolled without blood tests. Physicians in-charge were blinded to the MDW result.

\section{Measurements}

After obtaining the informed consent from the patients, their data, including age, gender, height, body weight, vital signs, comorbidities (diabetes mellitus, hypertension, coronary artery disease, chronic obstructive lung disease, asthma, malignancies, congestive heart failure, and chronic kidney disease.), were recorded. The coordinator carried out the laboratory testing (CBC count and differentiation count, BUN, creatinine, blood sugar, $\mathrm{Na}, \mathrm{K}$, total bilirubin, prothrombin time, lactic acid, and procalcitonin) at the hospital's central laboratory. MDW along with $\mathrm{CBC}$ and differential count were measured using Beckman Coulter $\mathrm{DxH} 900^{\circledR}$, according to the manufacturer's suggestion. The sample was processed and measured within 2 hours after collection.

Two separate emergency physicians reviewed the final diagnosis or admission after discharge from the hospital and assigned patients into four groups. The "non-infection" group: patients with no diagnosis related to an infection and did not meet the SIRS criteria; the "SIRS" group: patients meeting SIRS criteria without any recognized infectious disease; the "Sepsis" group: patients meeting the SIRS criteria with any known infection; the "Sepsis-3" group: patients who met the sepsis-3 criteria of 2017 if both qSOFA score 
and SOFA score were $\geqq 2$. If the initial assignment did not match, the consensus was made after discussion. Both physicians were blinded to the MDW and procalcitonin data during the process.

\section{Outcomes}

The primary outcome was the diagnostic accuracy of both MDW and PCT presented with the AUC, sensitivity, specificity, positive predictive value (PPV), and negative predictive value (NPV) in predicting sepsis and sepsis-3. The secondary outcome was the diagnostic accuracy of WBC count along with MDW in predicting sepsis and sepsis-3.

\section{Statistical analysis}

Continuous variables were expressed as mean \pm SD (standard deviation), and categorical variables were indicated as frequency (\%). We used boxplots to draw continuous variables. Logistic regression analysis was performed to identify the effect of six variables on the four groups. Diagnostic ability was evaluated in terms of the AUC, sensitivity, specificity, PPV, and NPV along with their $95 \% \mathrm{Cl}$ values. The initial cutoff values were obtained using the Youden index approach, which was optimized iteratively to maximize the sensitivity and specificity. Both WBC count and MDW were dichotomized to 0 and 1 based on their values falling into the normal or abnormal category. WBC count was normal if the recovered value was between 4,000 and $11,000 / \mu \mathrm{L}$. MDW was normal when its recovered value was $<20.5$.

\section{Results}

Characteristics of study subjects: from June to September 2020, we screened all the patients admitted to the ED during convenient hours with symptoms suggesting potential sepsis. Among all 124,702 ED patients, 709 met the inclusion criteria, however, 307 patients were excluded because of exclusion criteria. The algorithm is shown in Fig. 1. We enrolled 402 patients for data analysis (Table 1). Two hundred and one patients $(50 \%)$ were male, and the mean patient age was $63.7 \pm 18.9$ years. Vital signs at the triage presented with mean were: body temperature $37.7 \pm 1.3{ }^{\circ} \mathrm{C}$, respiratory rate (RR) $20.0 \pm 4.0 / \mathrm{min}$, and heart rate (HR) $105.0 \pm 21.1 / \mathrm{min}$. Systolic and diastolic blood pressure at arrival were $130.3 \pm 29.5$ and $75.0 \pm$ $17.1 \mathrm{mmHg}$ and $26.4 \%$ and $38.1 \%$ of patients had diabetes and hypertension, respectively. In addition, $29.6 \%$ of the patients had known malignancy. Pneumonia (lower respiratory tract infection) was the most common infection focus $(26.7 \%)$, followed by urinary tract infection $(16.2 \%)$, intra-abdominal infection (11.5\%), and soft tissue infection (4.2\%). WBC count and monocyte distribution width were $11.5 \pm 17.9 / \mu \mathrm{L}$ and $22.6 \pm 5.3$, respectively. The average serum lactate and procalcitonin were $20.3 \pm 16.3 \mathrm{mg} / \mathrm{dL}$ and 2.5 $\pm 11.1 \mathrm{ng} / \mathrm{mL}$, respectively. Blood culture was positive in 59 patients $(14.7 \%)$, and overall mortality was $9.4 \%$. 
Table 1

Baseline characteristics of the patients

\begin{tabular}{|c|c|}
\hline & ALL \\
\hline Total patient number & 402 \\
\hline Age (yrs) & $63.7 \pm 18.9$ \\
\hline Gender, Male N(\%) & $201(50)$ \\
\hline Body temperature () & $37.7 \pm 1.3$ \\
\hline Respiratory rate (/min) & $20.0 \pm 4.0$ \\
\hline Heart rate (/min) & $105.0 \pm 21.1$ \\
\hline Systolic blood pressure (mmHg) & $130.3 \pm 29.5$ \\
\hline Diastolic blood pressure (mmHg) & $75.0 \pm 17.1$ \\
\hline White blood cell count $(1,000 / u L)$ & $11.5 \pm 17.9$ \\
\hline Platelet (1,000/uL) & $234.7 \pm 121.8$ \\
\hline Segment (\%) & $78.1 \pm 12.3$ \\
\hline Lymphocyte (\%) & $13.2 \pm 9.8$ \\
\hline Monocyte (\%) & $6.7 \pm 5.2$ \\
\hline $\mathrm{Cr}(\mathrm{mg} / \mathrm{dL})$ & $1.5 \pm 1.8$ \\
\hline $\operatorname{ALT}(\mathrm{U} / \mathrm{L})$ & $41.4 \pm 60.9$ \\
\hline Total bilirubin (mg/dL) & $1.3 \pm 1.1$ \\
\hline PT (sec) & $14.0 \pm 3.2$ \\
\hline INR & $1.3 \pm 0.3$ \\
\hline aPTT (sec) & $27.9 \pm 6.8$ \\
\hline Lactate (mg/dL) & $20.3 \pm 16.3$ \\
\hline MDW & $22.6 \pm 5.3$ \\
\hline Procalcitonin (ng/mL) & $2.5 \pm 11.1$ \\
\hline \multicolumn{2}{|l|}{ Comorbidities N(\%) } \\
\hline Diabetes & $106(26.4)$ \\
\hline Hypertension & 153(38.1) \\
\hline Chronic obstructive pulmonary disease & $17(4.2)$ \\
\hline
\end{tabular}




\begin{tabular}{|ll|}
\hline & ALL \\
\hline Chronic kidney disease & $47(11.7)$ \\
\hline Congestive heart failure & $13(3.2)$ \\
\hline Malignancy & $119(29.6)$ \\
\hline Stroke & $25(6.5)$ \\
\hline Infection Focus N(\%) & \\
\hline Respiratory tract infection & $107(26.7)$ \\
\hline Urinary tract infection & $65(16.2)$ \\
\hline Intra-abdominal infection & $46(11.5)$ \\
\hline Soft tissue infection & $17(4.2)$ \\
\hline Others & $166(41.4)$ \\
\hline Bacteremia, N(\%) & $59(14.7)$ \\
\hline In-hospital mortality, N(\%) & $35(9.4)$ \\
\hline
\end{tabular}

Main results: Based on the chart review by two separate emergency physicians blinded to both MDW and PCT results, we assigned the patients to four distinct groups as follows (Table 2), the "non-infection" group $(n=64,15.9 \%)$, the "infection" group $(n=82,20.4 \%)$, the "sepsis" group $(n=202,50.2 \%)$, and the "sepsis-3" group ( $n=54,13.4 \%)$. 
Table 2

Patient characteristics in different groups

\begin{tabular}{|c|c|c|c|c|c|}
\hline & $\begin{array}{l}\text { Non- } \\
\text { infection }\end{array}$ & Infection & Sepsis & Sepsis-3 & $\begin{array}{l}\mathrm{p}- \\
\text { value }\end{array}$ \\
\hline$N(\%)$ & $64(15.9)$ & $82(20.4)$ & $202(50.2)$ & $54(13.4)$ & \\
\hline Age (yrs) & $60.1 \pm 17.8$ & $62.3 \pm 20.2$ & $62.8 \pm 18.9$ & $73.2 \pm 15.7$ & 0.001 \\
\hline Gender, Male N(\%) & $29(45.31)$ & $38(46.34)$ & 103(50.99) & $31(57.41)$ & 0.5191 \\
\hline Body temperature () & $37 \pm 1.15$ & $37.17 \pm 0.93$ & $38.2 \pm 1.16$ & $37.56 \pm 1.46$ & $<.0001$ \\
\hline Respiratory rate (/min) & $20 \pm 3.72$ & $17.94 \pm 2.27$ & $19.69 \pm 3.59$ & $24.59 \pm 4.59$ & $<.0001$ \\
\hline Heart rate $(/ \mathrm{min})$ & $96.63 \pm 22.9$ & $\begin{array}{l}89.95 \pm \\
15.39\end{array}$ & $\begin{array}{l}112.43 \pm \\
17.3\end{array}$ & $\begin{array}{l}109.65 \pm \\
24.2\end{array}$ & $<.0001$ \\
\hline $\begin{array}{l}\text { Systolic blood pressure } \\
(\mathrm{mmHg})\end{array}$ & $\begin{array}{l}130.5 \pm \\
29.46\end{array}$ & $128 \pm 29.97$ & $\begin{array}{l}135.34 \pm \\
27.57\end{array}$ & $\begin{array}{l}114.8 \pm \\
30.66\end{array}$ & 0.0005 \\
\hline $\begin{array}{l}\text { Diastolic blood pressure } \\
(\mathrm{mmHg})\end{array}$ & $76.27 \pm 18.8$ & $\begin{array}{l}75.45 \pm \\
16.55\end{array}$ & $76.3 \pm 15.66$ & $\begin{array}{l}68.09 \pm \\
19.49\end{array}$ & 0.0046 \\
\hline $\begin{array}{l}\text { White blood cell count } \\
(1,000 / u L)\end{array}$ & $8.78 \pm 4.99$ & $7.93 \pm 3.34$ & $12.06 \pm 5.95$ & $\begin{array}{l}18.25 \pm \\
46.35\end{array}$ & $<.0001$ \\
\hline Platelet $(1,000 / u L)$ & $\begin{array}{l}250.85 \pm \\
113.13\end{array}$ & $\begin{array}{l}229.24 \pm \\
102.37\end{array}$ & $\begin{array}{l}237.46 \pm \\
127.41\end{array}$ & $\begin{array}{l}214.59 \pm \\
130.87\end{array}$ & 0.2594 \\
\hline Segment (\%) & $74.01 \pm 9.85$ & $\begin{array}{l}73.99 \pm \\
12.36\end{array}$ & $80.4 \pm 11.74$ & $\begin{array}{l}80.34 \pm \\
14.13\end{array}$ & $<0.0001$ \\
\hline Lymphocyte (\%) & $17.39 \pm 8.89$ & $16.62 \pm 9.15$ & $10.99 \pm 8.88$ & $\begin{array}{l}11.24 \pm \\
11.74\end{array}$ & $<.0001$ \\
\hline Monocyte (\%) & $6.5 \pm 2.94$ & $7.02 \pm 5.14$ & $7.07 \pm 6.17$ & $5.48 \pm 3.12$ & 0.142 \\
\hline $\mathrm{Cr}(\mathrm{mg} / \mathrm{dL})$ & $1.65 \pm 2.03$ & $1.47 \pm 1.7$ & $1.43 \pm 1.74$ & $1.79 \pm 1.65$ & 0.1564 \\
\hline Total bilirubin (mg/dL) & $1.43 \pm 1.5$ & $0.93 \pm 0.59$ & $1.23 \pm 1.01$ & $1.66 \pm 1.65$ & 0.2965 \\
\hline INR & $1.33 \pm 0.33$ & $1.16 \pm 0.12$ & $1.25 \pm 0.26$ & $1.45 \pm 0.32$ & 0.0003 \\
\hline MDW & $18.54 \pm 3.33$ & $20.78 \pm 3.98$ & $23.46 \pm 4.64$ & $26.77 \pm 6.98$ & $<0.0001$ \\
\hline Procalcitonin $(\mathrm{ng} / \mathrm{mL})$ & $0.2 \pm 0.29$ & $0.44 \pm 1.5$ & $1.93 \pm 7.91$ & $\begin{array}{l}10.25 \pm \\
24.56\end{array}$ & $<.0001$ \\
\hline Bacteremia, N(\%) & $1(1.56)$ & $3(3.7)$ & $35(17.33)$ & $20(37.04)$ & $<.0001$ \\
\hline In-hospital mortality, N(\%) & $1(1.85)$ & $2(2.63)$ & $13(6.81)$ & 19(36.54) & $<.0001$ \\
\hline
\end{tabular}


Among the four groups, age and gender distribution were similar. Patients in the sepsis group had the highest initial body temperature $\left(38.2 \pm 1.2^{\circ} \mathrm{C}, \mathrm{p}<0.001\right)$. Patients in the sepsis-3 group had a higher respiratory rate $(24.6 \pm 4.6 / \mathrm{min})$ and lower systolic blood pressure $(114.8 \pm 30.66 \mathrm{mmHg}, \mathrm{p}<0.001)$. There was no difference regarding the underlying condition of the patients. Laboratory examinations, including BUN, sodium, potassium, total bilirubin, alanine aminotransferase, were not different between groups. Sepsis and Sepsis-3 groups had higher serum creatinine and INR $(p<0.05)$. WBC count in each group was $8.8 \pm 5.0,7.9 \pm 3.3,12.1 \pm 6.0$, and $18.3 \pm 46.41,000 / \mathrm{LL}$, respectively (Fig. $2 A, p<0.05$ ). MDW in each group was measured to be $18.5 \pm 3.3,20.8 \pm 4.0,23.5 \pm 4.6$, and $26.8 \pm 7.0$, respectively (Fig. $2 B, p<0.05$ ). The estimated PCT in each group was $0.2 \pm 0.3,0.4 \pm 1.5,1.9 \pm 7.9$, and $10.3 \pm 24.6 \mathrm{ng} / \mathrm{mL}$, respectively (Fig. 2C, p 0.05).

Next, we evaluated the diagnostic accuracy of MDW, PCT and MDW + WBC with AUC analysis. For predicting sepsis, the AUC of MDW and PCT was 0.753 (0.701-0.804) and 0.704 (0.65-0.759), respectively (Table 3 and Fig. 3A). The best MDW cutoff values were estimated to be 19.3 and. Based on the earlier reports and our data, we defined normal WBC count in the range of 4,000 to $11,000 / \mu \mathrm{L}$.[28] When normal WBC count and normal MDW were used as the cutoff, the AUC predicting sepsis and sepsis-3 was 0.784 (0.738-0.829), and 0.699 (0.631-0.768), respectively. The sensitivity, specificity, PPV, and NPV of MDW using 20 as the cutoff in predicting sepsis were $86.4 \%, 54.2 \%, 76.4 \%$, and $70 \%$, compared to $32.9 \%, 88 \%, 82.5 \%$, and $43.4 \%$ using $0.5 \mathrm{ng} / \mathrm{mL}$ as the PCT cutoff value. On combing MDW and WBC count, the sensitivity and NPV further increased to $93.4 \%$ and $80.3 \%$, respectively. In predicting sepsis-3, the AUC of MDW and PCT was 0.722 (0.652-0.792), and 0.733 (0.663-0.802), with the best MDW cutoff value of 23.4 and $0.31 \mathrm{ng} / \mathrm{mL}$ (Fig. 3B). When the WBC count was added to the model, the AUC was 0.700 (0.631-0.768). MDW, using 20 as cutoff, exhibited sensitivity, specificity, PPV, and NPV of $90.6 \%, 37.1 \%, 18.7 \%$, and $96.1 \%$, respectively, compared to $49.1 \%, 78.6 \%, 26.8 \%$, and $90.6 \%$ when 0.5 $\mathrm{ng} / \mathrm{mL}$ PCT was used as cutoff. When WBC count was combined with MDW, the sensitivity and NPV were $86.8 \%$ and $95.3 \%$, respectively. 
Table 3

Diagnostic accuracy of MDW and PCT in predicting sepsis and sepsis-3

\begin{tabular}{|llllllll|}
\hline & AUC & 95\% C.I. & $\begin{array}{l}\text { Cut- } \\
\text { off }\end{array}$ & Sensitivity & Specificity & PPV & NPV \\
\hline MDW & 0.753 & $(0.701,0.804)$ & 19.26 & 0.8642 & 0.5423 & 0.7636 & 0.7000 \\
\hline Procalcitonin & 0.704 & $(0.650,0.759)$ & 0.10 & 0.7778 & 0.5634 & 0.7530 & 0.5970 \\
\hline $\begin{array}{l}\text { WBC_N+ } \\
\text { MDW_N }\end{array}$ & 0.784 & $(0.738,0.829)$ & - & 0.9342 & 0.4577 & 0.7467 & 0.8025 \\
\hline MDW & 0.753 & $(0.701,0.804)$ & 20.00 & 0.8066 & 0.5634 & 0.7597 & 0.6299 \\
\hline Procalcitonin & 0.704 & $(0.650,0.759)$ & 0.50 & 0.3292 & 0.8803 & 0.8247 & 0.4340 \\
& AUC & $95 \%$ C.I. & Cut- & Sensitivity & Specificity & PPV & NPV \\
\hline MDW & 0.722 & $(0.652,0.792)$ & 23.41 & 0.6981 & 0.6747 & 0.2552 & 0.9333 \\
\hline Procalcitonin & 0.733 & $(0.664,0.802)$ & 0.31 & 0.6792 & 0.6657 & 0.2449 & 0.9286 \\
\hline $\begin{array}{l}\text { WBC_N+ } \\
\text { MDW_N }\end{array}$ & 0.700 & $(0.631,0.768)$ & - & 0.8679 & 0.4277 & 0.1949 & 0.9530 \\
\hline MDW & 0.722 & $(0.652,0.792)$ & 20.00 & 0.9057 & 0.3705 & 0.1868 & 0.9609 \\
\hline $\begin{array}{l}\text { Procalcitonin } \\
\text { AUC: Area under receiver operating characteristic (ROC) curve; PPV: positive predictive value; NPV: }\end{array}$ \\
\hline negative predictive value & 0.733 & $(0.664,0.802)$ & 0.50 & 0.4906 & 0.7861 & 0.2680 & 0.9063 \\
\hline
\end{tabular}

\section{Discussion}

In 2017, sepsis was re-defined as life-threatening organ dysfunction caused by an overwhelming host immune response. If the patient meets the criteria of sepsis-3, the mortality remains as high as greater than $30 \%$. Delayed recognition and treatment of sepsis can result in worse patient outcomes. The new definition focused on the identification of the patients with the worst prognosis. However, it took thorough laboratory tests, including liver function, renal function, and arterial blood gas analysis, to complete the SOFA score. Some studies have suggested that it is not feasible for an emergency physician to recognize or exclude patients with the potential risk of sepsis and decide patient disposition.[32-34] This study showed that MDW only or combined with WBC count can be used as a readily available biomarker in the ED to predict bacterial infection.

To date, most clinicians utilize CRP and PCT for early diagnosis of sepsis in the ED. The performance of PCT was better than that of CRP in earlier studies.[14, 20,35] As an early screening tool for sepsis, its sensitivity and specificity were around $80 \%$ and $75 \%$, respectively. Nonetheless, the accuracy of PCT in predicting patients fulfilling sepsis-3 criteria remains low. PCT is generally used to exclude severe sepsis because of its high NPV. The attempt to develop a more accurate diagnostic modality had never stopped. 
Presepsin, interleukin-6, pentraxin-3, and neutrophil/lymphocyte ratio were some of the biomarkers developed and investigated recently.[24, 36, 37] Nonetheless, not all studies suggested better performance of these biomarkers than PCT in predicting sepsis. Thus PCT remains by far the most common biomarker of sepsis. MDW is different from most of the biomarkers mentioned because it can be estimated as a part of the CBC count estimation without extra-expanse, at least in the health care system of Taiwan. It could be advantageous if the diagnostic accuracy is comparable to or even better than the biomarkers we are currently using.

Fever is the most common presenting symptom of infection. Nonetheless, patients with sepsis may present to the ED with a wide variety of clinical signs, including malaise, shortness of breath, conscious disturbance, hypotension, etc.[5] Early diagnosis depends on clinical suspicion and the test results of various biomarkers. We intended to design a study that is more relevant to the clinical setting. For this, we enrolled patients with not only fever but also various primary complaints suggestive of sepsis. The study excluded patients who did not undergo any blood test according to clinical judgment. The setting was similar to the actual practice in the ED. The mortality of patients fulfilling sepsis-3 was also similar to that mentioned in the previous report. Fever was not found to be a good indicator of severe sepsis. Sepsis-3 criteria predicted in-hospital mortality was better than previous sepsis criteria in our patient group. The mortality rate was also similar to that mentioned in the previous report.

Sepsis-3 focused on those patients with the worst outcome. Even so, in most cases, emergency physicians had to decide when to discharge with acceptable risk. Biomarkers with higher sensitivity helped us to initiate the sepsis treatment protocol as early as possible. Previous sepsis criteria were more feasible for early screening. The accuracy of MDW alone or MDW and WBC count in predicting sepsis were both better than that of PCT. The suggested cutoff value of MDW was 20, which was similar to that in the previous report. Besides, MDW also provided better sensitivity than PCT at $0.5 \mathrm{ng} / \mathrm{mL}$ cutoff value. MDW, in this case, was a better biomarker than PCT for early sepsis screening.

In terms of predicting sepsis-3, both MDW and PCT had comparable AUC. However, using 20 as the cutoff value, MDW provided significantly higher sensitivity and NPV than those by PCT at $0.5 \mathrm{ng} / \mathrm{mL}$ cutoff value. The accuracy further increased while WBC count was added. PCT was observed to be a specific but not a sensitive biomarker, especially in predicting sepsis-3. It is challenging to exclude critical patients using PCT in the clinical setting. Serial PCT follow-up is another way to predict patient outcomes.[38, 39] MDW, at the cutoff value of 20 , provided an excellent negative predictive value to exclude sepsis-3. Overall, MDW had better performance in both early screening of sepsis and patient outcome prediction. WBC count had relatively good sensitivity but low specificity traditionally.[6] Combining MDW and WBC count increased both sensitivity and NPV in predicting sepsis but not in sepsis-3. Nonetheless, the specificity decreased accordingly. Clinicians must interpretate the result with caution to minimize unnecessary antibiotic usage or admission.

Monocytes, including macrophages and dendritic cells, serve as the first-line responder of innate and adaptive immunity. Microorganisms activate the immune system through various pattern recognition 
receptors on monocytes. MDW can measure the size and shape change of monocytes during the activation and differentiation process. This makes MDW a unique and novel biomarker compared to other protein-based markers. It takes hours for the target cells to start protein production to complete the transcription and translation processes. The differentiation of monocytes in the circulation begins relatively early in the sepsis cascade, and this could be one of the reasons for the increased sensitivity of MDW in the sepsis diagnosis.

One of the limitations of MDW is that the value is not available in patients with a monocyte percentage less than $1 \%$ in the peripheral blood sample. The left-shift of WBC subtypes is one of the earliest used biomarkers in the sepsis diagnosis. In this study, we assumed that the low monocyte percentage was due to the WBC left-shift. That is, patients with low monocyte percentage might have a higher chance of sepsis. In our study, MDW was not measurable in 22 patients, and $20(91 \%)$ and $10(45 \%)$ patients were in the sepsis and sepsis-3 group, respectively. Although the possibility of sepsis or sepsis-3 was higher in these patients, we suggested the physicians use other sepsis biomarkers if the MDW value were not available.

In most health care systems, PCT is a relatively expensive biomarker. It is thrice as costly as CBC/DC or CRP in Taiwan's National Health Insurance program. An emergency physician can not order PCT in all suspected patients for sepsis screening. MDW, as part of the CBC/DC report, could be an economical yet accurate screening tool in the ED. PCT can be used as the second-line sepsis biomarker if the diagnosis is still doubtful.

\section{Conclusions}

Early recognition of septic patients remains challenging. Clinical suspicion remains even in the era of various biomarkers and artificial intelligence. Biomarkers help physicians to decide the patient's disposition confidently. Our results showed that MDW increased among patients with infection by severity. In conclusion, MDW is a more sensitive biomarker than PCT in predicting sepsis/sepsis-3 in the ED. MDW $<20$ shows a higher NPV to exclude sepsis-3. Thus, it could be a useful screening tool for sepsis diagnosis in the ED.

\section{Limitations}

Our results should be interpreted in the context of some limitations. First, this study is a single-center study in only one ED. The results might not be generalizable to all Eds. We might need a multi-center study to validate the results. Second, we enrolled patients with specific symptoms instead of consecutive patients in the ED and excluded those without laboratory testing. Nonetheless, we believe that it best fits the ED practice model.

\section{List Of Abbreviations}


1. AUC, area under curve

2. $\mathrm{CBC}$, complete blood count

3. CPD, cell population data

4. CRP, C-reactive protein

5. ED, emergency department

6. IL-6, interleukin-6

7. MDW, monocyte distribution width

8. NPV, negative predictive value

9. PCT, procalcitonin

10. PPV, positive predictive value

11. SD, standard deviation

12. SIRS, systemic inflammatory response syndrome

\section{Declarations}

\section{Ethics approval and consent to participate}

The study was approved by the Institution Review Board of Chang Gung Memorial Hospital (No. 201900442B0) and registered to the ClinicalTrial.gov (NCT04322942).

\section{Consent for publication}

This study does not include any individual data in any form. (including individual details, images or videos). Personal consent of study was collected in the enrollment process according to the IRB regulation.

\section{Availability of data and materials}

The datasets used and/or analysed during the current study are available from the corresponding author on reasonable request.

\section{Competing interests}

No authors have any potential conflicts of interest.

\section{Funding}

This study was supported by funds provided by Beckman Coulter ${ }^{\circledR}$, Taiwan to $\mathrm{CHL}$ and CJN. Beckman Coulter provided personal salary to the research assistant and laboratory kit necessary to complete the assay.

\section{Author contributions:}


CHL and CJN conceived the study, designed the trial, and obtained research funding. CHL and CJS supervised the conduct of the trial and data collection. CHL undertook recruitment of participating centers and patients and managed the data, including quality control. CHL, CHC, THS, CYC and SYG provided statistical advice on study design and analyzed the data. CHL drafted the manuscript, and all authors contributed substantially to its revision. CJN takes responsibility for the paper as a whole.

\section{References}

1. Singer M, Deutschman CS, Seymour CW, Shankar-Hari M, Annane D, Bauer M, Bellomo R, Bernard GR, Chiche JD, Coopersmith CM et al: The Third International Consensus Definitions for Sepsis and Septic Shock (Sepsis-3). JAMA : the journal of the American Medical Association 2016, 315(8):801810.

2. Seymour CW, Liu VX, Iwashyna TJ, Brunkhorst FM, Rea TD, Scherag A, Rubenfeld G, Kahn JM, Shankar-Hari M, Singer M et al: Assessment of Clinical Criteria for Sepsis: For the Third International Consensus Definitions for Sepsis and Septic Shock (Sepsis-3). JAMA : the journal of the American Medical Association 2016, 315(8):762-774.

3. Shankar-Hari M, Phillips GS, Levy ML, Seymour CW, Liu VX, Deutschman CS, Angus DC, Rubenfeld GD, Singer M, Sepsis Definitions Task F: Developing a New Definition and Assessing New Clinical Criteria for Septic Shock: For the Third International Consensus Definitions for Sepsis and Septic Shock (Sepsis-3). JAMA : the journal of the American Medical Association 2016, 315(8):775-787.

4. Focus on sepsis. Nature medicine 2012, 18(7):997.

5. Angus DC, van der Poll T: Severe sepsis and septic shock. The New England journal of medicine 2013, 369(9):840-851.

6. Rhodes A, Evans LE, Alhazzani W, Levy MM, Antonelli M, Ferrer R, Kumar A, Sevransky JE, Sprung CL, Nunnally ME et al: Surviving Sepsis Campaign: International Guidelines for Management of Sepsis and Septic Shock: 2016. Intensive care medicine 2017, 43(3):304-377.

7. Kumar A, Roberts D, Wood KE, Light B, Parrillo JE, Sharma S, Suppes R, Feinstein D, Zanotti S, Taiberg $L$ et al: Duration of hypotension before initiation of effective antimicrobial therapy is the critical determinant of survival in human septic shock. Critical care medicine 2006, 34(6):1589-1596.

8. Ferrer R, Martin-Loeches I, Phillips G, Osborn TM, Townsend S, Dellinger RP, Artigas A, Schorr C, Levy MM: Empiric antibiotic treatment reduces mortality in severe sepsis and septic shock from the first hour: results from a guideline-based performance improvement program. Critical care medicine 2014, 42(8):1749-1755.

9. Gaieski DF, Mikkelsen ME, Band RA, Pines JM, Massone R, Furia FF, Shofer FS, Goyal M: Impact of time to antibiotics on survival in patients with severe sepsis or septic shock in whom early goaldirected therapy was initiated in the emergency department. Critical care medicine 2010, 38(4):10451053.

10. Hayden GE, Tuuri RE, Scott R, Losek JD, Blackshaw AM, Schoenling AJ, Nietert PJ, Hall GA: Triage sepsis alert and sepsis protocol lower times to fluids and antibiotics in the ED. The American journal 
of emergency medicine 2016, 34(1):1-9.

11. Li CH, Yang RB, Pang JH, Chang SS, Lin CC, Chen CH, Chen HY, Chiu TF: Procalcitonin as a biomarker for bacterial infections in patients with liver cirrhosis in the emergency department. Academic emergency medicine : official journal of the Society for Academic Emergency Medicine 2011, 18(2):121-126.

12. Chan YL, Tseng CP, Tsay PK, Chang SS, Chiu TF, Chen JC: Procalcitonin as a marker of bacterial infection in the emergency department: an observational study. Critical care 2004, 8(1):R12-20.

13. Covino M, Piccioni A, Bonadia N, Onder G, Sabia L, Carbone L, Candelli M, Ojetti V, Murri R, Franceschi $\mathrm{F}$ : Early procalcitonin determination in the emergency department and clinical outcome of community-acquired pneumonia in old and oldest old patients. European journal of internal medicine 2020, 79:51-57.

14. Chang CH, Tsao KC, Hu HC, Huang CC, Kao KC, Chen NH, Yang CT, Tsai YH, Hsieh MJ: Procalcitonin and C-reactive protein cannot differentiate bacterial or viral infection in COPD exacerbation requiring emergency department visits. International journal of chronic obstructive pulmonary disease 2015, 10:767-774.

15. Matthaiou DK, Ntani G, Kontogiorgi M, Poulakou G, Armaganidis A, Dimopoulos G: An ESICM systematic review and meta-analysis of procalcitonin-guided antibiotic therapy algorithms in adult critically ill patients. Intensive care medicine 2012, 38(6):940-949.

16. Prkno A, Wacker C, Brunkhorst FM, Schlattmann P: Procalcitonin-guided therapy in intensive care unit patients with severe sepsis and septic shock-a systematic review and meta-analysis. Crit Care 2013, 17(6):R291.

17. Westwood M, Ramaekers B, Whiting P, Tomini F, Joore M, Armstrong N, Ryder S, Stirk L, Severens J, Kleijnen J: Procalcitonin testing to guide antibiotic therapy for the treatment of sepsis in intensive care settings and for suspected bacterial infection in emergency department settings: a systematic review and cost-effectiveness analysis. Health Technol Assess 2015, 19(96):v-xxv, 1-236.

18. Kondo Y, Umemura Y, Hayashida K, Hara Y, Aihara M, Yamakawa K: Diagnostic value of procalcitonin and presepsin for sepsis in critically ill adult patients: a systematic review and meta-analysis. $J$ Intensive Care 2019, 7:22.

19. Jekarl DW, Lee S, Kim M, Kim Y, Woo SH, Lee WJ: Procalcitonin as a prognostic marker for sepsis based on SEPSIS-3. J Clin Lab Anal 2019, 33(9):e22996.

20. Wu CW, Wu JY, Chen CK, Huang SL, Hsu SC, Lee MT, Chang SS, Lee CC: Does procalcitonin, Creactive protein, or interleukin- 6 test have a role in the diagnosis of severe infection in patients with febrile neutropenia? A systematic review and meta-analysis. Supportive care in cancer : official journal of the Multinational Association of Supportive Care in Cancer 2015, 23(10):2863-2872.

21. Li X, Wu J, Mao W: Evaluation of the neutrophil-to-lymphocyte ratio, monocyte-to-lymphocyte ratio, and red cell distribution width for the prediction of prognosis of patients with hepatitis B virus-related decompensated cirrhosis. J Clin Lab Anal 2020:e23478. 
22. Kadiyoran C, Zengin O, Cizmecioglu HA, Tufan A, Kucuksahin O, Cure MC, Cure E, Kucuk A, Ozturk MA: Monocyte to Lymphocyte Ratio, Neutrophil to Lymphocyte Ratio, and Red Cell Distribution Width are the Associates with Gouty Arthritis. Acta Medica (Hradec Kralove) 2019, 62(3):99-104.

23. Sahin C, Varim C: Neutrophil to Lymphocyte Ratio, Platelet to Lymphocyte Ratio, Mean Platelet Volume and Red Cell Distribution Width Measures in Bells Palsy. Open Access Maced J Med Sci 2017, 5(1):14-18.

24. Song J, Park DW, Moon S, Cho HJ, Park JH, Seok H, Choi WS: Diagnostic and prognostic value of interleukin-6, pentraxin 3, and procalcitonin levels among sepsis and septic shock patients: a prospective controlled study according to the Sepsis-3 definitions. BMC infectious diseases 2019, 19(1):968.

25. Skibsted S, Bhasin MK, Aird WC, Shapiro NI: Bench-to-bedside review: future novel diagnostics for sepsis - a systems biology approach. Crit Care 2013, 17(5):231.

26. Celik IH, Demirel G, Aksoy HT, Erdeve O, Tuncer E, Biyikli Z, Dilmen U: Automated determination of neutrophil VCS parameters in diagnosis and treatment efficacy of neonatal sepsis. Pediatric research 2012, 71(1):121-125.

27. Lee AJ, Kim SG: Mean cell volumes of neutrophils and monocytes are promising markers of sepsis in elderly patients. Blood Res 2013, 48(3):193-197.

28. Crouser ED, Parrillo JE, Seymour C, Angus DC, Bicking K, Tejidor L, Magari R, Careaga D, Williams J, Closser DR et al: Improved Early Detection of Sepsis in the ED With a Novel Monocyte Distribution Width Biomarker. Chest 2017, 152(3):518-526.

29. Crouser ED, Parrillo JE, Seymour CW, Angus DC, Bicking K, Esguerra VG, Peck-Palmer OM, Magari RT, Julian MW, Kleven JM et al: Monocyte Distribution Width: A Novel Indicator of Sepsis-2 and Sepsis-3 in High-Risk Emergency Department Patients. Critical care medicine 2019, 47(8):1018-1025.

30. Crouser ED, Parrillo JE, Martin GS, Huang DT, Hausfater P, Grigorov I, Careaga D, Osborn T, Hasan M, Tejidor L: Monocyte distribution width enhances early sepsis detection in the emergency department beyond SIRS and qSOFA. J Intensive Care 2020, 8:33.

31. Polilli E, Sozio F, Frattari A, Persichitti L, Sensi M, Posata R, Di Gregorio M, Sciacca A, Flacco ME, Manzoli L et al: Comparison of Monocyte Distribution Width (MDW) and Procalcitonin for early recognition of sepsis. PloS one 2020, 15(1):e0227300.

32. Engoren M, Seelhammer T, Freundlich RE, Maile MD, Sigakis MJG, Schwann TA: A Comparison of Sepsis-2 (Systemic Inflammatory Response Syndrome Based) to Sepsis-3 (Sequential Organ Failure Assessment Based) Definitions-A Multicenter Retrospective Study. Crit Care Med 2020, 48(9):12581264.

33. Lindner HA, Kirschning T, Fairley AM, Oster ME, Weiss C, Schneider-Lindner V: Earlier Recognition of Sepsis and Septic Shock With Sepsis-3 Criteria- It's Still Early Days!Shock 2020, 53(6):779-780.

34. Tian H, Zhou J, Weng L, Hu X, Peng J, Wang C, Jiang W, Du X, Xi X, An Y et al: Accuracy of qSOFA for the diagnosis of sepsis-3: a secondary analysis of a population-based cohort study. $J$ Thorac Dis 2019, 11(5):2034-2042. 
35. Oliveira CF, Botoni FA, Oliveira CR, Silva CB, Pereira HA, Serufo JC, Nobre V: Procalcitonin versus Creactive protein for guiding antibiotic therapy in sepsis: a randomized trial. Critical care medicine 2013, 41(10):2336-2343.

36. Tambo M, Taguchi S, Nakamura Y, Okegawa T, Fukuhara H: Presepsin and procalcitonin as predictors of sepsis based on the new Sepsis-3 definitions in obstructive acute pyelonephritis. $B M C$ Urol 2020, 20(1):23.

37. van Oers JAH, de Jong E, Kemperman H, Girbes ARJ, de Lange DW: Diagnostic Accuracy of Procalcitonin and C-reactive Protein Is Insufficient to Predict Proven Infection: A Retrospective Cohort Study in Critically III Patients Fulfilling the Sepsis-3 Criteria. J App/ Lab Med 2020, 5(1):62-72.

38. Tromp M, Lansdorp B, Bleeker-Rovers CP, Gunnewiek JM, Kullberg BJ, Pickkers P: Serial and panel analyses of biomarkers do not improve the prediction of bacteremia compared to one procalcitonin measurement. J Infect 2012, 65(4):292-301.

39. Guan J, Lin Z, Lue H: Dynamic change of procalcitonin, rather than concentration itself, is predictive of survival in septic shock patients when beyond $10 \mathrm{ng} / \mathrm{mL}$. Shock 2011, 36(6):570-574.

\section{Figures}




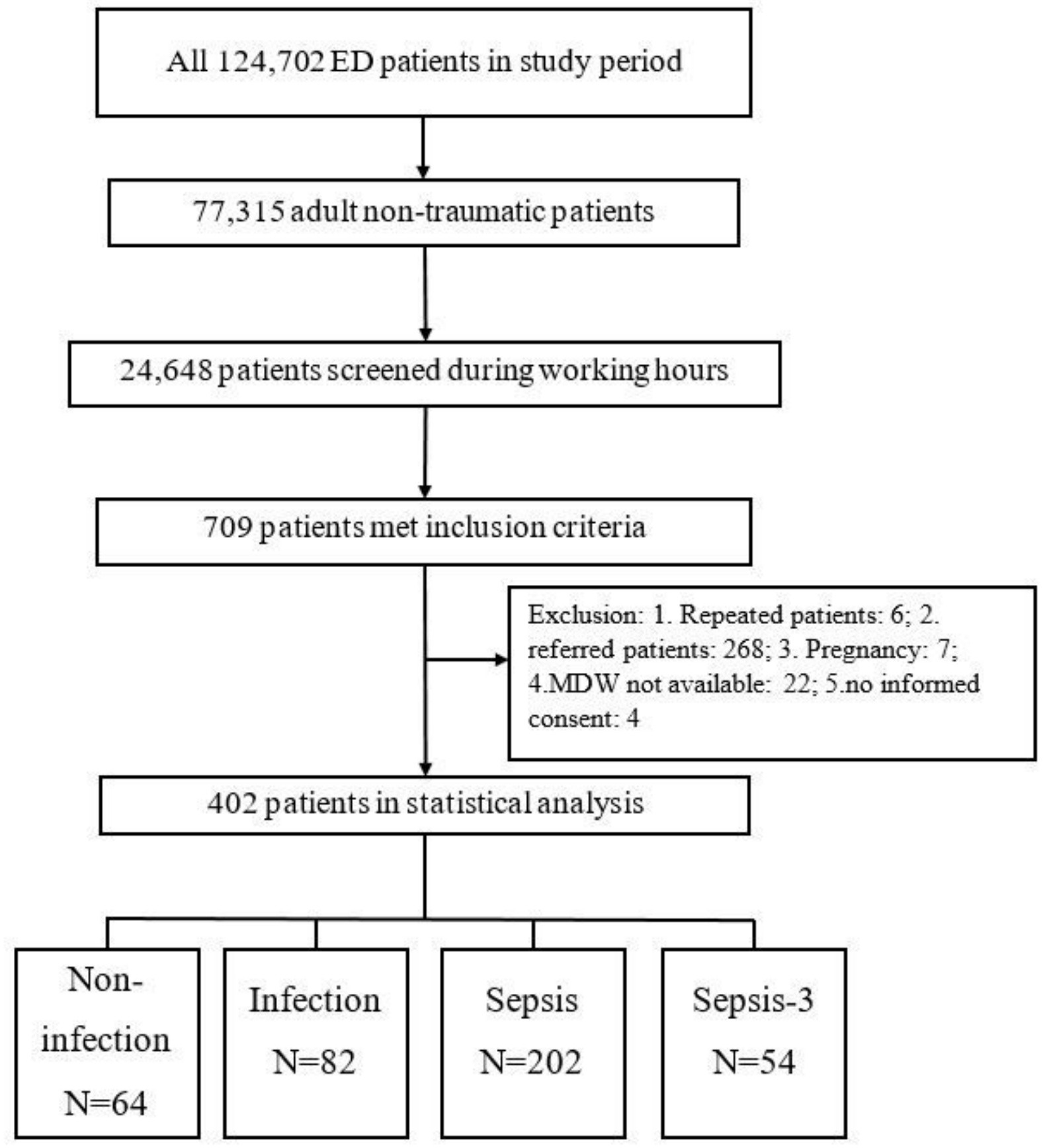

Figure 1

Study enrollment algorithm. 402 patients were enrolled for data analysis from June 2019 to September 2020. 
A

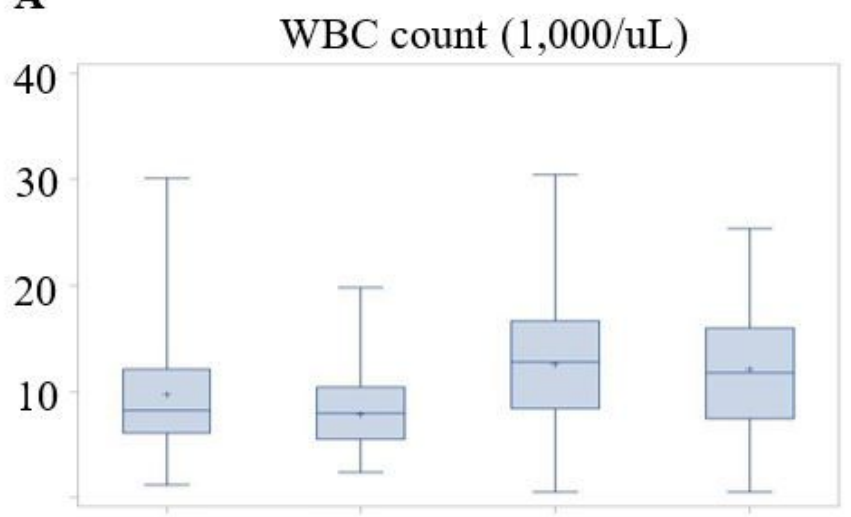

Non- Infection Sepsis Sepsis-3 infection
B

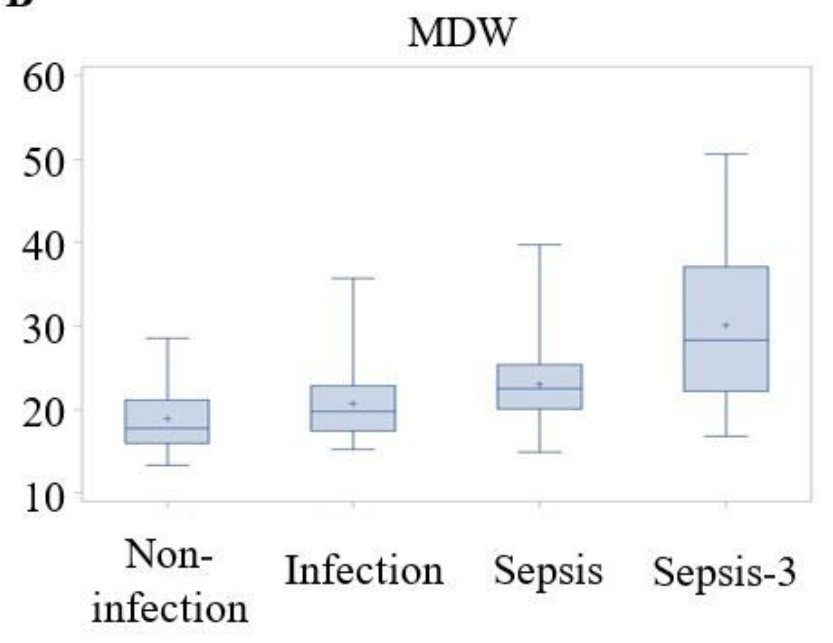

C

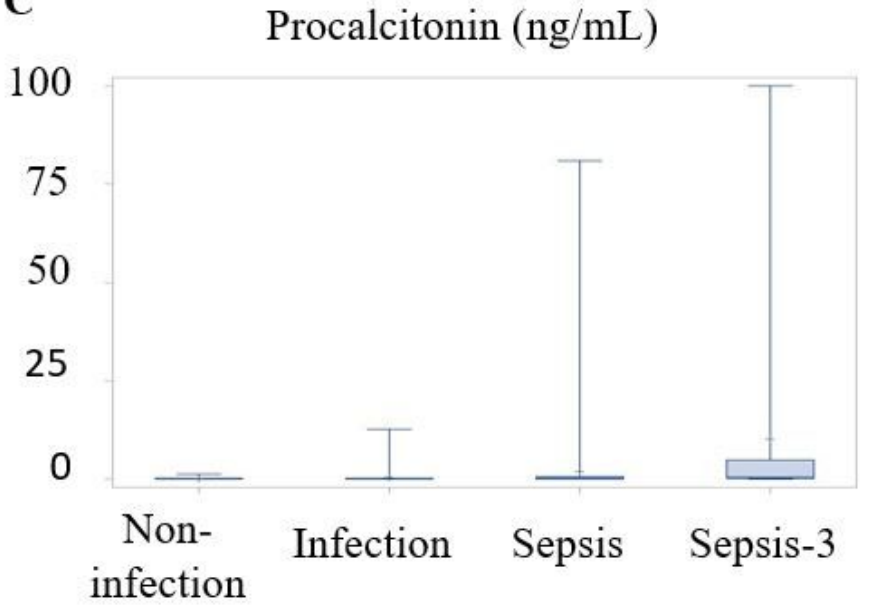

\section{Figure 2}

Main laboratory results measured in each group. There was no significant difference in WBC count between 4 groups (A). MDW (B) and procalcitonin (C) measurement increased in patients with infection. Patient met sepsis-3 criteria had the highest MDW and PCT level. 
$\mathbf{A}$

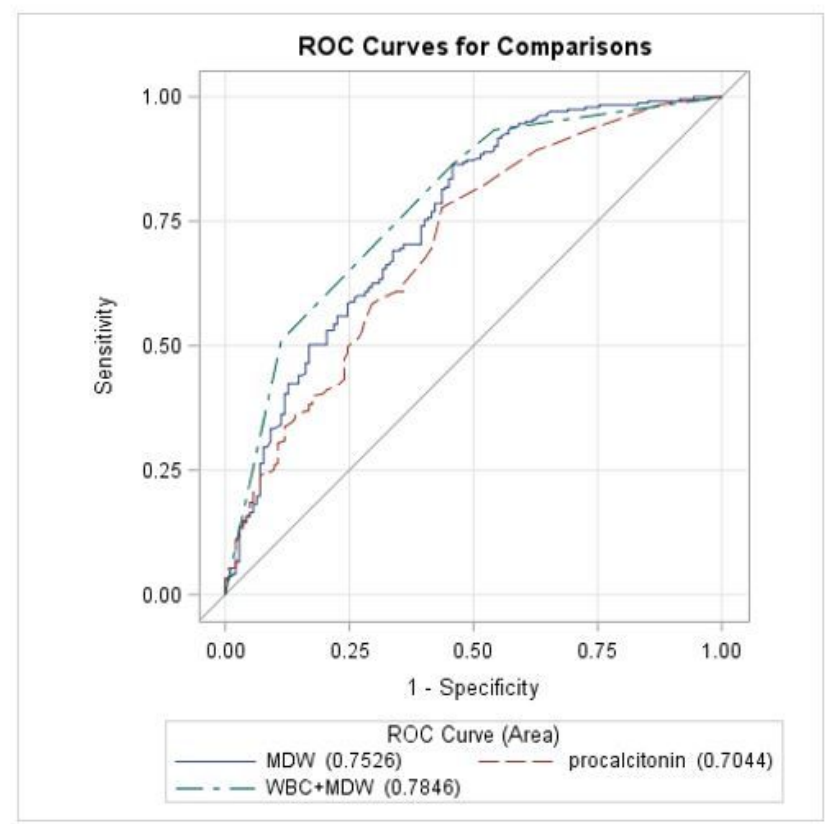

B

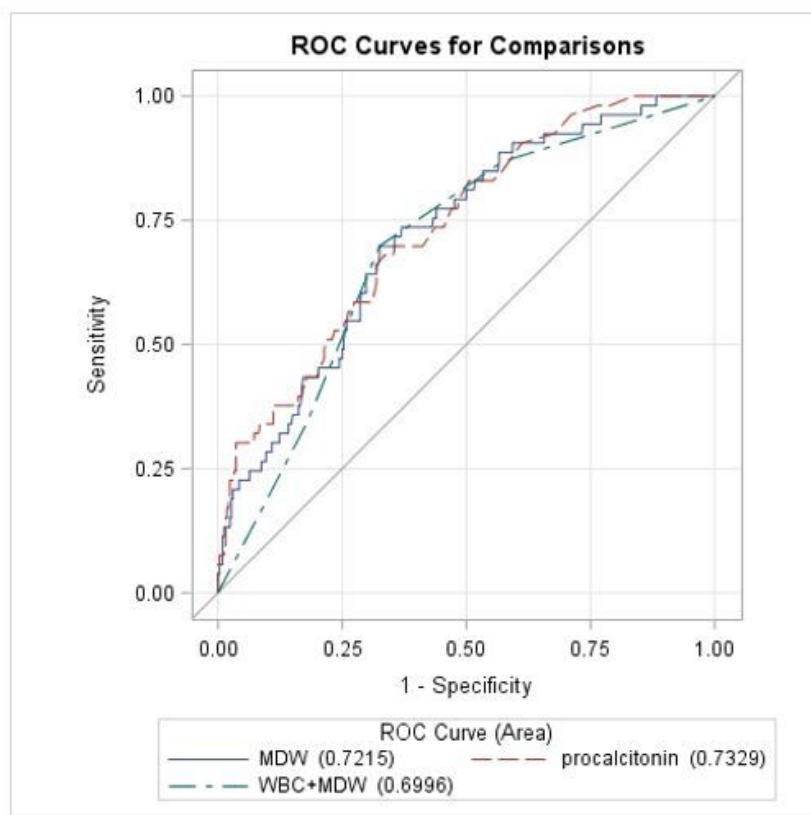

\section{Figure 3}

Receiver operating characteristic (ROC) curve analysis of MDW and PCT in predicting sepsis (A) and sepsis-3 (B). 